\title{
Study on the Intelligent Recognition Method for the Maturity Grade of Fresh Corn Ear based on Computer Vision
}

\author{
Huihui Wang \\ Mechanical Engineering \& Automation College \\ Dalian Polytechnic University \\ Dalian,China \\ whh419@126.com \\ Yonghai Sun \\ Biological \& Agricultural Engineering College \\ Jilin University \\ Changchun,China \\ Yan Lv \\ Mechanical Engineering \& Automation College \\ Dalian Polytechnic University \\ Dalian,China
}

\author{
Xueheng Tao \\ Information Science \& Engineering College \\ Dalian Polytechnic University \\ Dalian,China
}

\author{
Xuejun Wang \\ Mechanical Engineering \& Automation College \\ Dalian Polytechnic University \\ Dalian,China \\ Jixin Yang \\ Mechanical Engineering \& Automation College \\ Dalian Polytechnic University \\ Dalian,China
}

\begin{abstract}
In order to realize the intelligent recognition for the maturity grade of fresh corn ear, intelligent inspection system was studied based on computer vision, which could automatically complete the collection and handling of ear graphic and the recognition of maturity of the corn ear. Based on the study, a kind of intelligent recognition method was put forward under the graphic of certain frequency domain. An energy chain was established, and the characters of energy spectrum was extracted through the two-dimensional inverse discrete Fourier transformation on the graphics collected. With the above characters, a probabilistic neural network was developed, the accuracy rate of the recognition method could be $96.7 \%$.
\end{abstract}

Keywords- fresh corn ear; maturity grade; computer vision; intelligent recognition; neural network

\section{INTRODUCTION}

Fresh corn ear contains many kinds of amino acid, vitamin, trace element and fatty acid etc, and possesses certain medical and health care function. With more attention paying on the nutritive value, demand of fresh corn ear increases gradually. Corn raw material sampling and online quality detection were accomplished by human. A large amount of manpower and material resources were expended using artificial detection. Fresh corn ear intelligent recognition is one of important determinants for corn's further processing enterprises production automation. Computer vision technology is widely applicated in intelligent detection, such as Category and figure of grain identification, crops recognition in the field, grading of fruit and vegetable. An auto-threshold value technology was proposed based on Otsu's threshold value technology by Suranjan Panigrahi, M.K.Misra,etc. It was improved with
Otsu's threshold value technology.This method is good at segmenting targets and background of corn ear image ${ }^{[1]}$. In YcrCb color modle, mean values of color features was computed and whiteness of corn kernel was extracted by $\mathrm{J}$. Liu. The research proposed a whiteness definition method, which is fast, accurate and simple ${ }^{[2]}$. Four corns (xhg, xn12,wn14 and white corn) were studied by Yang Shuqin. Chromaticity and shape feature were used as characters to establishe BP neural network.This method could accomplish the four corns recognition. Because marked difference between white corn and others, it has the most accurate recognition results ${ }^{[3]}$. Because of heavy intensity of labour, detection results are greatly influenced by fatigue and other environmental factors. It is almost impossible get any fresh corn one it has passed the milk-ripe stage and the nutritional value of such corn will be much lower compared with the fresh corn. To automatically recognize the over-matured corn ears is a critical issue for the realization of automation of the enterprises engaging in the manufacturing of fresh corn products.

\section{INSPECTION SYSTEM}

The inspection system mainly consists of conveying device, graphic processing device, grade classification device and automation control device, major devices were as shown in figure 1 and 2 . The corn ears to be inspected will be sent into the graphic processing device through the conveying device. The processing device will conduct graphic collection and process the graphics based on the calculation methods from Fourier transform to get the grade classification of the corns. The automation control system will control the grade classification device according to the grade classification signals collected and transfer the over- 
matured corn ears to the designated place with a dividing plate to realize the intelligent recognition.

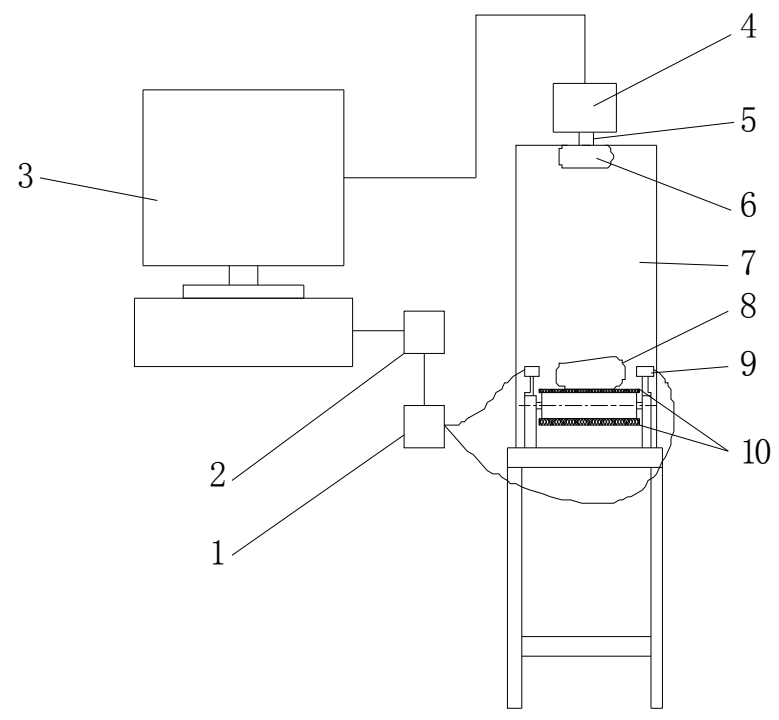

Figure 1. Inspection system

1.image grabbe; 2 . data acquisition card;

3. computer; 4. camera; 5. camera lens; 6. light source;

7. decteting box; 9 . photoelectric switch; 10. conveyor

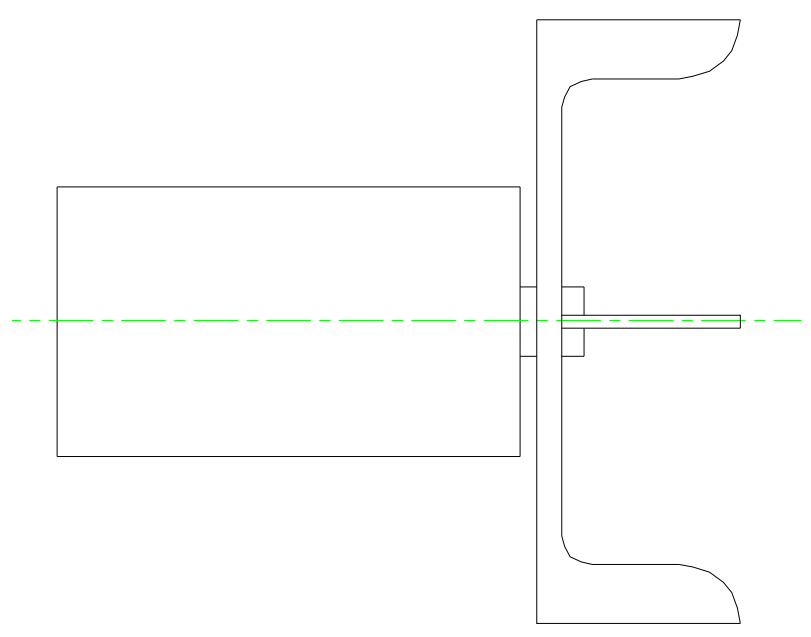

Figure 2. Grade classification device

\section{FOURIER TRANSFORM AND CHARACTER EXTRACTION}

\section{A. Fourier Transform}

To use the Fourier character to analyze graphics is a typical graphic analysis method of frequency domain. However, the two-dimensional graphics transformed from Fourier is very difficult to understand. Therefore, this paper has conducted the power spectrum analysis for the graphics transformed from inverse discrete Fourier and studied its application in the process of maturity inspection ${ }^{[4]}$.

Firstly, it is necessary to accomplish one dimension fourier transform . We assume the one dimensional function $\mathrm{f}(\mathrm{x})$ have limited interval points and limited poles, which is absolutely integrable. Define the fourier transform fuction is

$$
F(\mu)=\int_{-\infty}^{+\infty} f(x) e^{-j 2 \pi \mu x} d x
$$

Here $\mathrm{x}$ is time domain variable, $\mathrm{y}$ is frequency domain. If $\omega=2 \pi \mu$,

$$
F(\omega)=\int_{-\infty}^{+\infty} f(x) e^{-j \omega x} d x
$$

Assume real part of $F(\mu)$ is $R(\omega)$, imaginary part is $I(\omega)$, fourier transform plurality expression is,

$F(\omega)=R(\omega)+I(\omega)$

$|F(\omega)|=R^{2}(\omega)+I^{2}(\omega)$

As for the two-dimensional graphics, it is necessary to convert the one dimensional graphic into two-dimensional graphics. Here we assume the two-dimensional function is $\mathrm{f}(\mathrm{x}, \mathrm{y})$,

$$
\begin{aligned}
& F(\mu, v)=\int_{-\infty}^{+\infty} \int_{-\infty}^{+\infty} f(x, y) e^{-j 2 \pi(\mu x+v y)} d x d y \\
& |F(\mu, v)|=\sqrt{R^{2}(\mu, v)+I^{2}(\mu, v)}
\end{aligned}
$$

Then the energy spectrum of the graphic is:

$$
E(\mu, v)=R^{2}(\mu, v)+I^{2}(\mu, v)
$$

Assume the size of the graphic is $\mathrm{M} \times \mathrm{N}$, then conduct inverse discrete Fourier transformation for the graphics for ears of fresh corns and get below equation:

$$
F(\mu, v)=\sum_{x=0}^{M-1} \sum_{y=0}^{N-1} f(x, y) e^{-j 2 \pi\left(\frac{\mu x}{M}+\frac{v y}{N}\right)}
$$

\section{B. Extraction of the Characters of Energy Spectrum}

Figure 3(a) has shown the original graphic of corn ears. The radial energy of the energy spectrum has close relationship with the direction of the texture of the corn ears and the energy will reach the maximum level in the direction of the vertical textures. The fresh corn ears at different maturity status will have different ear texture character. Therefore, based on the analysis of the size and distribution of the strength of the energy spectrum, the paper has studied the characters of the texture to extract the information related with the maturity grade of corn ears. 


\section{Original Graphic of Corn Ear}

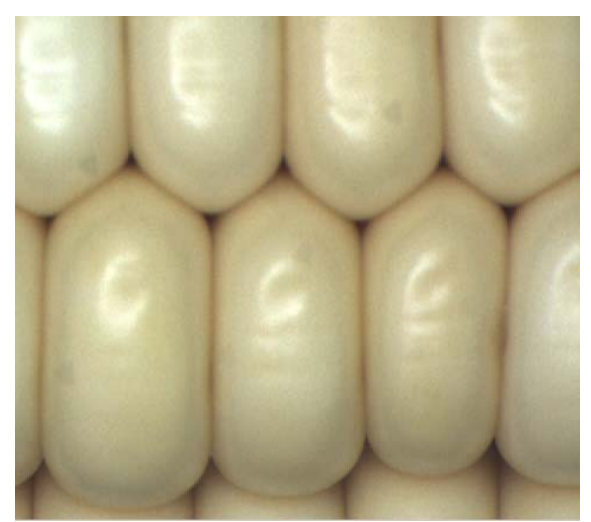

(a)

\section{Graphic of Energy Spectrum}

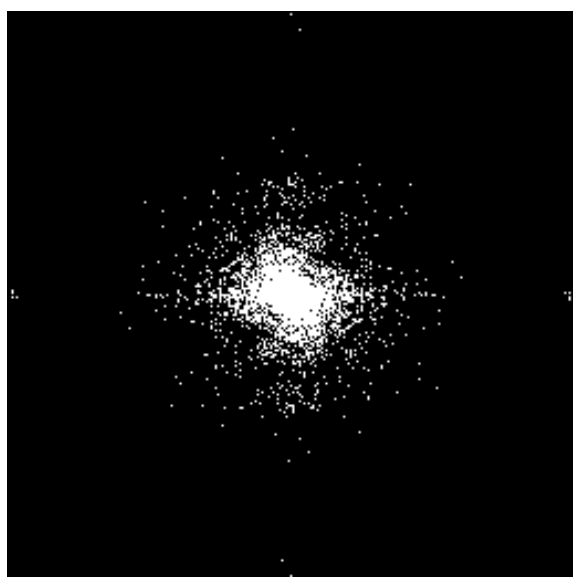

(b)

Energy Ring of Energy Spectrum

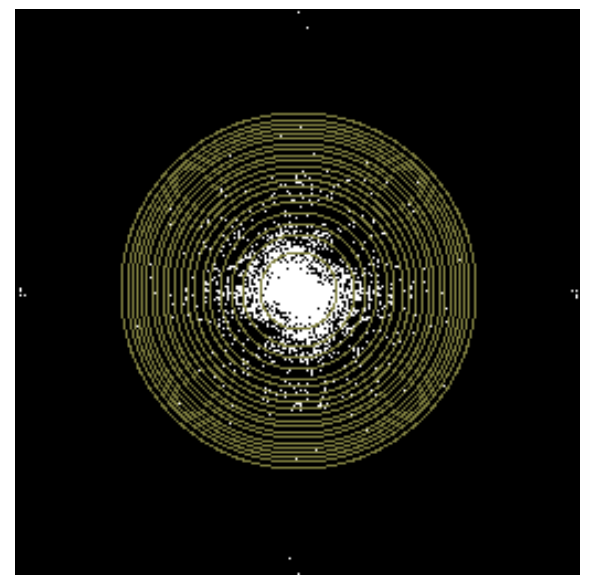

(c)

Figure 3. Corn Ear and Its Energy Spectrum

The graphic of energy spectrum as shown in Fig 3(b) could be achieved through the two-dimensional discrete
Fourier transformation of the partial graphic of the corn ear. Checking the shape of the energy spectrum, we could find the energy spectrum is spreading outward in the shape similar to a ring. With the center of the energy spectrum, we have drawn out the concentric rings as shown in Fig3(c) with same area with each other. In the paper, we name the concentric ring as energy ring. In order to analyze and study the energy spectrum based on the energy distribution within the energy rings, we have collected 75 partial graphics of fresh corn ears in different maturity grades. Based on theshape and distribution of the energy spectrum graphics, we found that the energy ring could get the best-distributed and most comprehensive covered energy spectrum when there are 20 energy rings with the ring area of pixel 2. For the comparability consideration, we have extracted the percentage between the energy in each energy ring and the total energy value as the characteristic vale of the texture analysis. Assume the size of the partial graphic is $\mathrm{L} \times \mathrm{W}$, the energy spectrum converted from the Fourier Transformation is:

$$
P(u, v)=|F(u, v)|^{2}
$$

The ratio get from the function is

$$
p_{i}=\frac{E_{i}}{\sum_{u=0}^{L} \sum_{v=0}^{W} P(u, v)}
$$

Where $E_{i}$ is the total energy within each energy ring.

The inspectors will conduct the recognition for the above mentioned corn ear and found the ear energy under different maturity grade is mainly distributed at the concentric ring close to the center of the circle. Therefore, the value of $p_{1}$ is the largest one and the value of $p_{i}$ will keep decreasing along with the outward spreading of the concentric ring as shown in table 1 . When i equals with 5 , the value of $p_{i}$ is very close to zero. Therefore, we just need to study the situations when the value of $i$ is between 1 and 5 for any energy spectrum analysis of the corn ears under different maturity grades.

TABLE I . THE VALUE RANGE OF CORN EAR UNDER DIFFERENT MATURITY GRADES

\begin{tabular}{|c|c|c|c|c|c|}
\hline $\begin{array}{c}\text { Maturity } \\
\text { Grade }\end{array}$ & $i=1$ & $i=2$ & $i=3$ & $i=4$ & $i=5$ \\
\hline $\begin{array}{c}\text { Over } \\
\text { matured } \\
\text { corn ears }\end{array}$ & $\begin{array}{c}{[0.64,} \\
1.00]\end{array}$ & $\begin{array}{c}{[0.00,} \\
0.25]\end{array}$ & $\begin{array}{c}{[0.00,} \\
0.07]\end{array}$ & $\begin{array}{c}{[0.00,} \\
0.04]\end{array}$ & $\begin{array}{c}{[0.00,} \\
0.00]\end{array}$ \\
\hline $\begin{array}{c}\text { Edible } \\
\text { Corn Ear }\end{array}$ & {$[0.31$,} & {$[0.19$,} & {$[0.06$,} & {$[0.02$,} & {$[0.00$,} \\
$0.62]$ & $0.28]$ & $0.14]$ & $0.09]$ & $0.07]$ \\
\hline
\end{tabular}

\section{ESTABLISHMENT OF THE RECOGNITION MODEL}

Select the appropriate probabilistic neural network suitable for the solving of the classification of maturity grade to recognize the corn ears that are over matured ${ }^{[5,6]}$. Randomly select 210 graphics of corn ears for the analysis 
including 120 graphics taken as the network training samples and 90 graphics served as the network testing samples. The quantity of nerve cells of layers input is 5 including $p_{1}, p_{2}, p_{3}, p_{4}$ and $p_{5}$. The recessive nerve cell will be defined by the network automatically.

Based on the testing of 90 corn ears, we come to the conclusion that the recognition of corn ear could get the best results with the highest speed when the constant value of the spread is 1.1. The output quantity of the nerve cells of layer is 2, which represents the corn ears have been divided into over matured grade and edible grade. Out put mode was used 0 and 1 , output vectors are as shown in table II. Compared with the ratification recognition of the corn ears, the accuracy rate of this intelligent recognition method could be as high as $96.7 \%$ as shown in table III.

TABLE II . GRADE OF OUTPUT VECTOR

\begin{tabular}{|c|c|c|}
\hline Maturity Grade & \multicolumn{2}{|c|}{ Output Vector } \\
\hline $\begin{array}{c}\text { Over matured } \\
\text { corn ears }\end{array}$ & 0 & 1 \\
\hline Edible Corn Ear & 1 & 0 \\
\hline
\end{tabular}

TABLE III. RECOGNITION RESULTS

\begin{tabular}{|c|c|c|c|}
\hline \multirow{2}{*}{$\begin{array}{c}\text { Article Grade } \\
\text { Classification }\end{array}$} & \multirow{2}{*}{$\begin{array}{c}\text { Quantity of } \\
\text { Testing } \\
\text { Samples }\end{array}$} & \multicolumn{2}{|c|}{$\begin{array}{c}\text { Results of the Grade } \\
\text { Classification }\end{array}$} \\
\cline { 3 - 4 } & & Over Matured & Edible Ears \\
\hline $\begin{array}{c}\text { Over Matured } \\
\text { Ears }\end{array}$ & 45 & 44 & 1 \\
\hline Edible Ears & 45 & 2 & 43 \\
\hline
\end{tabular}

\section{CONCLUSION}

With the application of the computer vision in the Fourier transformation and energy spectrum extraction of the corn ear characters based on the current maturity grade recognition status of the fresh corn ears, the intelligent recognition for the over matured ears and edible ears through probabilistic neural network could achieve the accuracy rate as high as $96.7 \%$.

\section{ACKNOWLEDGMENT}

This study is supported by the Doctoral Startup Project of Liaoning Province Science and Technology Plan and Liaoning Province Department of Education General Scientific and Technological Research Projects, the project numbers are 20121098 and L2012193 respectively, I would like to express my sincere gratitude here.

\section{REFERENCES}

[1] PANIGRAHI S , MISRA M K , BERN C, "Background Segmentation and Dimensional Measurment of Corn Germplasm," Transactions of the ASAE, vol. 38, Jan. 1995, pp. 291-297.

[2] LIU J and PAULSEN M R, "Corn Whiteness Measurement and Classfication Using Machine Vision,” Transactions of the ASAE, vol. 43, 2000, pp. 757-763.
[3] Shuqin Yang, Jifeng Ning and Dongjian He, "Identification of corn breeds by BP neural network,” Journal of Northwest A\&F University, vol. 32(supp), 2004, pp. 162-164.

[4] Yunlong Zhou, Zhenru Fan and Yaolei Su, "Identification method of flow regine based on images texture features by fourier transform and probablistic neural network in gas-solid fluidized bed's," Control and Instruments In Chemical Industry, vol. 36, 2009, pp. 38-42.

[5] KUO LIANG, CHUNG and WAN YUCHEN, "Fast adaptive PNNbased thresholding algorithms," Pattern Recognition,vol 36, Dec. 2003, pp. 2793-2804.

[6] CHING HAN CHEN, CHIA TE CHU. "High performance iris recognition based on 1-D circular feature extraction and PSO-PNN classifier," Expert Systems with Applications, vol. 36, 2009, pp. 10351-10356. 